\title{
Matéria orgânica e textura do solo em veredas conservadas e antropizadas no bioma Cerrado ${ }^{1}$
}

\author{
Ricardo F. de Sousa ${ }^{2}$, Jorge L. do $\mathrm{N}_{\text {ascimento }}{ }^{3}$, Eliana P. Fernandes ${ }^{3}$, \\ Wilson M. Leandro ${ }^{3} \&$ Alfredo B. de Campos ${ }^{4}$
}

\begin{abstract}
RESU MO
As veredas são ecossistemas úmidos, geralmente associados a solos hidromórficos e ao afloramento do lençol freático, ocorrendo com frequência nas proximidades das nascentes e cursos d'água da região do Cerrado. Este trabalho objetivou estudar os solos de veredas situadas no bioma Cerrado, em ambientes conservados e antropizados (em áreas agrícolas e de pecuária), por meio da determinação da textura e da matéria orgânica do solo. Três veredas foram selecionadas para amostragem de solo, sendo: uma conservada, circundada por vegetação natural; uma área antropizada, com pastagem em seu entorno e uma outra, também antropizada, com culturas anuais (agricultura) em seu entorno. As amostras de solo foram coletadas em diferentes profundidades, ao longo de linhas de referência dispostas segundo sua posição no relevo, nos terços superior, médio e inferior de uma das vertentes, acompanhando de modo aproximado o sentido da linha de drenagem da vereda. Verificou-se que os teores de argila na região inferior do relevo são maiores em ambientes antropizados e os teores de silte são maiores na vereda adjacente à área agrícola. No terço inferior das vertentes os teores de matéria orgânica são menores em veredas adjacentes às áreas com pastagens e agricultura.
\end{abstract}

Palavras-chave: áreas úmidas, propriedades do solo, solos hidromórficos, uso da terra

\section{O rganic matter and texture of the soil in conserved and altered wetlands in the Cerrado biome}

\section{ABSTRACT}

Veredas (a type of wetland) are humid ecosystems, generally associated to hydromorphic soils and shallow water table, which occur frequently in the neighborhood of the springs and watercourses in the Cerrado region. The objective of this work was to study wetland soils located in undisturbed (native forest) and disturbed (agriculture and pasture) environments by means of determination of the soil texture and organic matter contents. Three w etlands were selected for this study: undisturbed wetland, surrounded by natural vegetation; disturbed wetland, surrounded by pasture areas; and disturbed wetland, surrounded by cultivated areas. Soil samples were collected at three different depths, following reference leveled lines defined, according to their positions in the relief, i.e., upper, middle and lower slope positions. The reference lines were approximately parallel to the direction of the wetland fluvial channel. It was verified that the clay contents in the lower portion of the slope were higher for the disturbed environments and the contents of silt were higher for the disturbed wetland surrounded by agricultural areas. The organic matter contents in the lower portion of the slope were lower for the disturbed wetlands.

Key words: soil properties, hydromorphic soils, land use

\footnotetext{
1 Parte da Dissertação de Mestrado do primeiro autor apresentada ao Programa de Pós-graduação em Agronomia da U FG

2 Instituto Federal de Educação, Ciência e Tecnologia de G oiás - IFG, Rua 75 n. 46, Centro, CEP 74055 -110, Goiânia, G O . Fone: (62) $3227-2835$. E-mail: ricardofs@ifgoias.edu.br. Bolsista FAPEG

EA/U FG, Campus Samambaia, Rodovia Goiânia - N ova Veneza, Km 0, CP 131, CEP 74001-970, Goiânia, G O. Fone: (62) 3521-1530. E-mail: jIn@agro.ufg.br; elianafernandes@agro.ufg.br; leandro@agro.ufg.br

${ }^{4}$ IESA/U FG, Campus Samambaia (Campus II), CP 131, CEP 74001-970, G oiânia, G O. Fone: (62) 3521-1184. E-mail: alfredo@iesa.ufg.br
} 


\section{INTRODUÇÃO}

A região do Cerrado se estende por cerca de 2 milhões de $\mathrm{km}^{2}$, abrangendo uma extensa área da América do Sul e aproximadamente $22 \%$ do território brasileiro. Sua ocupação, sobretudo a partir da segunda metade do século XX, foi marcada pela expansão e intensificação das atividades agropecuárias (Silva, 2000; Klink \& Machado, 2005; Durigan et al., 2007). Ocorreu, então, um processo de grandes transformações com modificação do modo de vida da população e das técnicas de produção, que passaram a ser realizadas com a utilização maciça de insumos (fertilizantes, agrotóxicos, combustíveis, maquinário etc.), o que ampliou muito a produção e a produtividade agrícola da região mas, em contrapartida, provocou também sensíveis impactos ambientais.

O tipo de uso que se aplica às terras pode estar diretamente ligado à modificação e degradação do solo (Centurion et al., 2001; Thomaz, 2007). A ocupação e o uso intensivo do solo, visando à exploração agropecuária, provocam e aceleram inúmeras alterações em suas características e propriedades morfológicas, físicas, químicas e biológicas, alterações estas que, em algumas situações, podem assumir caráter negativo com relação ao sistema solo-água-planta (Lima et al., 1992; Liu et al., 2006; Oliveira et al., 2010), resultando em sérios impactos sobre os ecossistemas e populações humanas.

No bioma Cerrado, embora predominem as fitofisionomias associadas a solos bem drenados, ocorrem também áreas úmidas, como as matas de galeria inundáveis, os campos úmidos e as veredas (Ratter et al., 1997; Ribeiro \& Walter, 1998). Áreas úmidas são ecossistemas naturais que sofrem inundação periódica ou permanente e onde a água é o fator determinante das condições bióticas e abióticas (Tiner, 1991; Keddy, 2000), devendo-se mencionar que estão entre os recursos ambientais mais ameaçados do planeta (Maltby, 1991; Turner, 1991; O'Connell, 2003).

As veredas são sistemas úmidos, geralmente associados a solos hidromórficos e ao afloramento do lençol freático, ocorrendo com frequência nas proximidades das nascentes ou nas bordas das matas de galeria que acompanham cursos d'água (Baruqui \& Santana, 1980; Ferreira, 1980; Ribeiro \& Walter, 1998). São, por isso, muito importantes para a manutenção do equilíbrio dos processos biogeoquímicos que regulam a disponibilidade e a qualidade dos recursos hídricos.

Com a ocupação do Cerrado, muitas áreas localizadas nos arredores das veredas estão sendo agricultadas ou utilizadas como pastagens (Araújo et al., 2002; Junk, 2002), não se respeitando, muitas vezes, os limites de proteção estabelecidos pela legislação, como áreas de preservação permanente (APP), que têm como função a conservação do solo e dos recursos hídricos (Delalibera et al., 2008). As veredas e seus solos, por serem sistemas conservadores de água, localizados próximos às nascentes e cursos d'água, devem ser preservados (Reatto et al., 1998) e protegidos de eventuais efeitos nocivos advindos das atividades antrópicas praticadas em seus arredores.

Em locais utilizados para o desenvolvimento de atividades agropecuárias é fundamental a adoção de sistemas de manejo que mantenham a qualidade do solo e da água (Reatto et al., 1998; Giboshi et al., 2006; Araújo et al., 2007). Deste modo, é importante a realização de estudos que possibilitem a compreensão e o dimensionamento de fenômenos relacionados à perda da qualidade do solo e à alteração das suas características, que podem também, dentro de um contexto biogeoquímico, estar associados a processos generalizados de degradação ambiental.

Assim, este estudo objetivou avaliar alguns dos atributos do solo de áreas úmidas (veredas) situadas em ambientes conservados e antropizados (em áreas agrícolas e de pecuária), no bioma Cerrado, razão por que se fez a determinação do teor de matéria orgânica e da textura do solo, segundo os métodos normalmente empregados nas práticas analíticas de rotina adotadas pelos laboratórios de análises de solo da região.

\section{Material e MÉTOdos}

O estudo foi realizado na região nuclear do bioma Cerrado, no estado de Goiás, em veredas situadas no município de Bela Vista de Goiás, distante cerca de 50 km de Goiânia, a capital do Estado. As coletas de solo foram feitas nos meses de abril e maio de 2008, em áreas localizadas entre os paralelos $16^{\circ} 48^{\prime} \mathrm{S}$ e $17^{\circ} 02^{\prime} \mathrm{S}$ e os meridianos $48^{\circ} 41^{\prime} \mathrm{W}$ e $48^{\circ} 49^{\prime} \mathrm{W}$.

O clima na região de realização da pesquisa é tropical chuvoso (tipo Aw, na classificação de Köppen), com precipitação média anual da ordem de $1500 \mathrm{~mm}$. Observa-se marcante estacionalidade no regime de precipitações, com estações chuvosa (primavera e verão) e seca (outono e inverno) bem definidas, sendo as chuvas concentradas principalmente entre outubro e abril (CPRM, 2001). Os locais de amostragem apresentam relevo plano a suave ondulado, com altitudes variando entre 910 e $950 \mathrm{~m}$.

Selecionaram-se três áreas para amostragem de solo, situadas em uma mesma sub-bacia hidrográfica, em ambientes conservados e antropizados, sendo: uma vereda conservada, circundada por vegetação natural (cerrado); uma antropizada, com ocorrência de pastagem em seu entorno e uma outra vereda, também antropizada, com a ocorrência de culturas anuais (agricultura) em seu entorno.

A vereda localizada em ambiente conservado apresentava, na ocasião do estudo, toda a sua região periférica caracterizada pela presença de vegetação natural de cerrado (sentido restrito) considerando-se, como tal, os tipos fitofisionômicos de formação savânica que são predominantes no bioma e que, portanto, caracterizam bem a região do Cerrado (Ribeiro \& Walter, 1998). Na área estudada esta vegetação se estendia em faixa marginal, além do limite do espaço brejoso e encharcado, com largura bem superior aos $50 \mathrm{~m}$ (mínimos), definidos pela legislação florestal como APP (CONAMA, 2002).

Com base em informações fornecidas por moradores locais e indícios verificados em remanescentes da vegetação, pôdese constatar que as veredas antropizadas apresentavam, originalmente, áreas periféricas cobertas pelo mesmo tipo de vegetação, ou seja, por cerrado sentido restrito. No entanto, essa vegetação nativa foi suprimida ao longo do tempo, como resultado do processo de ocupação das terras da região (antropização). Dentre as áreas de estudo localizadas em ambiente antropizado, considerando-se o período de 
amostragem, uma apresentava o entorno ocupado por pastagens cultivadas, com predominância de capim braquiária (Brachiaria sp.), enquanto a outra tinha o entorno submetido à atividade agrícola de cultivo de grãos (especialmente as culturas de milho e soja).

As amostras de solo foram coletadas dentro dos limites das áreas de vereda em estudo, definidos pela vegetação distinta observada no ambiente encharcado das veredas e nas áreas secas adjacentes e, também, pela presença de solos brejosos, sujeitos à saturação por água (solos hidromórficos). As coletas foram feitas ao longo de linhas de referência dispostas segundo sua posição no relevo, nos terços superior, médio e inferior de uma das vertentes acompanhando, de modo aproximado, o sentido da linha de drenagem da vereda.

Foram colhidas amostras em três profundidades ou camadas de solo: 0-10 cm; 10-20 cm e 20-40 cm. A amostragem foi feita com o uso de trado holandês ou pá, optando-se pela ferramenta mais adequada à condição do solo no momento da coleta.

As amostras foram compostas por cinco subamostras obtidas dentro de faixas definidas ao longo das linhas de referência para amostragem, observando-se sua disposição no relevo, com coleta de solo na região superior da área, próximo ao limite ou borda da vereda, na porção média (meio) e na região de fundo, próximo ao talvegue. A amostragem foi realizada considerando-se, tanto quanto possível, a homogeneidade do solo nas glebas (faixas) definidas para a coleta das amostras, com três repetições para cada amostra coletada.

As amostras de solo coletadas foram secadas ao ar e peneiradas, com a fração menor que $2 \mathrm{~mm}$ sendo posteriormente submetida às análises de laboratório. A análise do teor de matéria orgânica do solo foi feita com uso de solução de dicromato de potássio em meio sulfúrico e a análise granulométrica (textural) foi realizada pelo método do densímetro, baseado na sedimentação das partículas constituintes do solo (EMBRAPA, 1997).

A estatística clássica foi empregada para identificar os efeitos das diferentes condições ambientais sobre as variáveis analisadas, com delineamento em blocos casualizados, em arranjo fatorial $3 \times 3 \times 3$ (três tipos de uso do entorno, três posições na vertente e três profundidades). Após as análises de variância foram efetuados os testes de Tukey a $5 \%$ de probabilidade nas médias dos tratamentos. Quando houve efeito significativo das interações entre fatores, a comparação entre médias foi feita após desdobramento do grau de liberdade; para a análise empregou-se o software SAS (Statistical Analysis System), versão 9.1 (SAS Institute, 2003).

\section{Resultados E DisCUSSÃo}

\section{Matéria orgânica}

Com base em critérios apresentados no Sistema Brasileiro de Classificação de Solos (SiBCS), os solos analisados no presente estudo, mesmo nas condições em que apresentaram teores mais elevados de matéria orgânica, não satisfazem, em relação ao teor de carbono, o requisito exigido para material orgânico e, portanto, são considerados material mineral, sendo constituídos essencialmente por compostos inorgânicos. No caso de material orgânico o conteúdo de compostos desta natureza deve impor preponderância de suas propriedades sobre os constituintes minerais (EMBRAPA, 2006).

De modo geral, os maiores teores de matéria orgânica do solo (MOS) foram observados na posição inferior da vertente das veredas pesquisadas, próximo ao talvegue, não havendo, nessa região, diferença significativa entre os teores de matéria orgânica nas diferentes camadas amostradas. Comparando-se os terços médio e superior das vertentes, observou-se que não houve diferenças significativas nas quantidades de MOS ocorrendo, no entanto, maior concentração deste componente do solo na camada superficial, com tendência observada nas camadas amostradas, de diminuição do teor de matéria orgânica, conforme o aumento da profundidade do solo (Tabela 1).

Tabela 1. Teores médios de matéria orgânica do solo (MOS) em diferentes profundidades de amostragem e posições nas vertentes

\begin{tabular}{cccc}
\hline \multirow{2}{*}{$\begin{array}{c}\text { Profundidade } \\
\text { (cm) }\end{array}$} & \multicolumn{3}{c}{ MOS (dag $\mathbf{~ d m}^{-3}$ ) } \\
\cline { 2 - 4 } & \multicolumn{3}{c}{ Posição na vertente } \\
\cline { 2 - 4 } $0-10$ & Terço inferior & Terço médio & Terço superior \\
$10-20$ & $9,50 \mathrm{aA}$ & $4,71 \mathrm{aB}$ & $4,01 \mathrm{aB}$ \\
$20-40$ & $8,19 \mathrm{aA}$ & $3,72 \mathrm{bB}$ & $3,21 \mathrm{bB}$ \\
& $10,26 \mathrm{aA}$ & $3,36 \mathrm{bB}$ & $2,56 \mathrm{cB}$ \\
\hline
\end{tabular}

Letras minúsculas comparam as profundidades (colunas) e maiúsculas comparam as posições na vertente (linhas). Médias seguidas da mesma letra não diferem estatisticamente pelo teste de Tukey a $5 \%$ de probabilidade. Médias dos diferentes usos do entorno

Em estudo realizado em veredas localizadas em dois ambientes geomórficos distintos, Ramos et al. (2006) verificaram que a matéria orgânica se apresenta como grande contribuinte para a fase sólida dos solos do terço inferior das vertentes das veredas de ambos os ambientes mas principalmente do terço inferior das vertentes das veredas de chapada. Os mesmos autores apresentam resultados em que os teores de MOS também são maiores na camada superficial dos terços médio e superior das vertentes dessas veredas.

Também se observou, em vereda estudada no estado de Minas Gerais, na zona de borda da área (região mais elevada), no limite com o cerrado, a ocorrência de melhor drenagem e, em contrapartida, menor teor de matéria orgânica (Guimarães et al., 2002). Este fato decorre, provavelmente, da decomposição e mineralização mais intensas da matéria orgânica, observadas numa condição de melhor aeração.

No presente estudo observou-se não haver diferenças significativas dos teores gerais de MOS entre os terços médio e superior das vertentes amostradas (Tabelas 1 e 2), não sendo verificadas, também, nessas mesmas posições das vertentes, quaisquer diferenças da quantidade de matéria orgânica, considerando-se os variados usos das terras adjacentes às veredas pesquisadas (Tabela 2). Comparando as áreas natural e antropizada de uma vereda vizinha a pastagens, Guimarães et al. (2002) não constataram diferenças expressivas entre as quantidades relativas de matéria orgânica no solo da região de borda da vereda.

$\mathrm{Na}$ posição mais baixa das vertentes das veredas estudadas (terço inferior) verificou-se, entretanto, comparativamente ao ambiente conservado, a ocorrência de teores de MOS 
Tabela 2. Teores médios de matéria orgânica do solo (MOS) em diferentes posições nas vertentes e condições de uso do entorno

\begin{tabular}{lccc}
\hline \multirow{3}{*}{ Posição na vertente } & \multicolumn{3}{c}{ MOS $\left(\right.$ dag dm d $^{-3}$ ) } \\
\cline { 2 - 4 } & \multicolumn{3}{c}{ Condição de uso do entorno } \\
\cline { 2 - 4 } Terço inferior & $13,21 \mathrm{aA}$ & $5,79 \mathrm{aC}$ & $8,94 \mathrm{aB}$ \\
Terço médio & $3,73 \mathrm{bA}$ & $3,81 \mathrm{bA}$ & $4,24 \mathrm{bA}$ \\
Terço superior & $3,04 \mathrm{bA}$ & $3,23 \mathrm{bA}$ & $3,50 \mathrm{bA}$ \\
\hline
\end{tabular}

Letras minúsculas comparam posições na vertente (colunas) e maiúsculas comparam os usos do entorno (linhas). Médias seguidas da mesma letra não diferem estatisticamente pelo teste de Tukey a $5 \%$ de probabilidade. Médias das diferentes camadas (profundidades de amostragem)

significativamente menores nas áreas com entorno submetido a atividades agropecuárias, sobremaneira na área agrícola (Tabela 2). Em estudo dos solos de áreas úmidas norteamericanas, comparando áreas úmidas naturais e áreas drenadas convertidas em pastagens, Sigua et al. (2006) observaram concentrações de MOS significativamente menores nas áreas de pastagem.

De modo semelhante, em estudo sobre o impacto do uso das terras sobre algumas propriedades do solo em áreas úmidas da África do Sul, constatou-se diminuição significativa da concentração de carbono no solo em locais onde existem áreas de pastagens e cultivos, relativamente a áreas úmidas naturais, sendo esta concentração calculada a partir de análises do carbono orgânico do solo. O estudo mencionado (Walters et al., 2006) evidencia os maiores teores de $\mathrm{C}$ em solos de áreas úmidas naturais, seguidos dos teores observados em pastagens e em sequência se verificam as menores concentrações de carbono em áreas cultivadas com milho, localizadas em antigas pastagens presentes nas áreas úmidas pesquisadas.

Embora esses últimos estudos apresentados não tenham sido realizados em condições ambientais idênticas às veredas do bioma Cerrado no Brasil, evidenciam, semelhantemente aos resultados obtidos no presente trabalho, tendência de modificação nos atributos do solo como resultado do uso agropecuário da terra. Desta forma se observou, nos três casos, poder ocorrer uma diminuição significativa dos teores de MOS ou de $\mathrm{C}$ orgânico nos solos de áreas úmidas antropizadas.

\section{Textura}

Segundo parâmetros indicados no SiBCS (EMBRAPA, 2006), os solos das veredas estudadas apresentaram textura argilosa em quase todas as condições amostradas (teores de argila entre 38 e $59 \mathrm{dag} \mathrm{dm}^{-3}$ ), com exceção da posição inferior da vertente da vereda conservada e, também, da camada superficial da mesma situação de relevo na vereda vizinha às pastagens onde foram verificados solos de textura média (com teores de argila e areia variando entre 21 e $30 \mathrm{dag} \mathrm{dm}^{-3}$ e entre 60 e $73 \mathrm{dag} \mathrm{dm}^{-3}$, respectivamente). Em veredas do Triangulo Mineiro, Ramos et al. (2006) relatam a ocorrência de solos com textura muito argilosa, argilosa ou média, conforme a superfície geomórfica relacionada e a posição no relevo.

De forma geral, os resultados das análises texturais mostram, nos ambientes estudados, os maiores teores de argila nas camadas subsuperficiais (10-20 cm e $20-40 \mathrm{~cm})$, enquanto o teor mais elevado de areia ocorre na região superficial do solo, ou seja, na camada de 0 a $10 \mathrm{~cm}$ (Tabela 3 ). Solos de várzeas e veredas, pertencentes à classe dos Gleissolos, localizados nas chapadas do Distrito Federal, são mencionados por RADAMBRASIL (1982) apresentando, do mesmo modo, perfil com maiores teores de argila nas camadas subsuperficiais, especialmente abaixo dos $40 \mathrm{~cm}$ de profundidade.

Tabela 3. Teores médios das frações argila e areia no solo em diferentes profundidades de amostragem

\begin{tabular}{ccc}
\hline Profundidade & Argila & Areia \\
\cline { 2 - 3 }$(\mathbf{c m})$ & \multicolumn{3}{c}{$\left(\right.$ dag dm $\left.^{-3}\right)$} \\
$0-10$ & $42,44 \mathrm{~b}$ & $40,04 \mathrm{a}$ \\
$10-20$ & $46,26 \mathrm{a}$ & $33,89 \mathrm{~b}$ \\
$20-40$ & $47,41 \mathrm{a}$ & $33,82 \mathrm{~b}$ \\
\hline
\end{tabular}

Médias seguidas da mesma letra não diferem estatisticamente pelo teste de Tukey a $5 \%$ de probabilidade. Médias das diferentes posições na vertente e usos do entorno

Ramos (2000), estudando solos de veredas localizadas na região do Triângulo Mineiro em superfícies elevadas, com 850 a $1000 \mathrm{~m}$ de altitude, de topos amplos e planos, assentadas sobre arenitos da formação Marília, observou resultado semelhante também com menores teores de argila na camada superficial e maiores quantidades relativas desta mesma fração nas camadas de subsuperfície; entretanto, o mesmo autor destaca a ocorrência de situação inversa com maiores teores de argila na superfície, relativamente às camadas mais profundas, em solos de veredas também no Triângulo Mineiro mas em superfície geomórfica com diferentes características.

Os teores da fração silte não apresentaram variações significativas entre as diferentes profundidades de amostragem, considerando-se distintamente cada posição da vertente, seja inferior, média ou superior (Tabela 4). Observouse, porém, de forma generalizada, menor quantidade relativa de silte na camada superficial da posição inferior da vertente, na região próxima ao talvegue, comparativamente à mesma camada das regiões média e superior das vertentes que constituem as veredas pesquisadas. Não houve variação significativa dos teores de silte nas porções mais elevadas (terços médio e superior), ou nas camadas subsuperficiais em quaisquer posições das vertentes estudadas (Tabela 4).

Tabela 4. Teores médios de silte no solo em diferentes profundidades de amostragem e posições nas vertentes

\begin{tabular}{cccc}
\hline \multirow{2}{*}{$\begin{array}{c}\text { Profundidade } \\
\text { (cm) }\end{array}$} & \multicolumn{3}{c}{ Silte $\left(\right.$ dag $\mathbf{~ d m}^{-3}$ ) } \\
\cline { 2 - 4 } & Posição na vertente \\
\cline { 2 - 4 } $0-10$ & $11,67 \mathrm{aB}$ & $21,33 \mathrm{aA}$ & $19,56 \mathrm{aA}$ \\
$10-20$ & $18,67 \mathrm{aA}$ & $20,33 \mathrm{aA}$ & $20,56 \mathrm{aA}$ \\
$20-40$ & $19,00 \mathrm{aA}$ & $18,89 \mathrm{aA}$ & $18,44 \mathrm{aA}$ \\
\hline
\end{tabular}

Letras minúsculas comparam as profundidades (colunas) e maiúsculas comparam as posições na vertente (linhas). Médias seguidas da mesma letra não diferem estatisticamente pelo teste de Tukey a $5 \%$ de probabilidade. Médias dos diferentes usos do entorno

O terço inferior das áreas estudadas neste trabalho apresenta os maiores teores de areia enquanto os terços médio e superior apresentam os teores mais elevados de argila, sendo que nas posições mais elevadas (média e superior) não foram observadas diferenças texturais significativas, considerandose distintamente cada condição de uso do entorno das veredas 
(Tabela 5). Deve-se observar, porém, que, conforme o ambiente de ocorrência, os solos de vereda podem variar substancialmente quanto à distribuição granulométrica nas diferentes posições da paisagem e também entre as diferentes camadas (Ramos, 2000).

Tabela 5. Teores de argila e areia no solo em diferentes posições das vertentes e condições de uso do entorno

\begin{tabular}{llll}
\hline \multicolumn{1}{c}{$\begin{array}{c}\text { Posição na } \\
\text { vertente }\end{array}$} & \multicolumn{3}{c}{ Condição de uso do entorno } \\
\cline { 2 - 4 } & \multicolumn{4}{c}{ Conservada } & Lavoura & Pasto \\
Terço inferior & $21,22 \mathrm{bB}$ & $42,11 \mathrm{bA}$ & $36,44 \mathrm{bA}$ \\
Terço médio & $50,11 \mathrm{aA}$ & $48,56 \mathrm{aA}$ & $52,78 \mathrm{aA}$ \\
Terço superior & $55,78 \mathrm{aA}$ & $51,44 \mathrm{aAB}$ & $49,89 \mathrm{aB}$ \\
\hline \multicolumn{4}{c}{ Areia $\left(\right.$ dag dm$\left.^{-3}\right)$} \\
Terço inferior & $66,22 \mathrm{aA}$ & $38,22 \mathrm{aB}$ & $46,44 \mathrm{aB}$ \\
Terço médio & $32,11 \mathrm{bA}$ & $28,33 \mathrm{bA}$ & $27,56 \mathrm{bA}$ \\
Terço superior & $26,22 \mathrm{bB}$ & $26,11 \mathrm{bB}$ & $32,00 \mathrm{bA}$ \\
\hline
\end{tabular}

Letras minúsculas comparam posições na vertente (colunas) e maiúsculas comparam os usos do entorno (linhas). Médias seguidas da mesma letra não diferem estatisticamente pelo teste de Tukey a $5 \%$ de probabilidade. Médias das diferentes camadas (profundidades de amostragem)

A variação de textura entre camadas dos solos nas veredas é resultado, possivelmente, da contribuição variável de sedimentos trazidos das partes mais altas da paisagem, indicando um processo de entulhamento das veredas que pode ter, como causa principal, a ação antrópica (Ramos, 2000). Martin \& Hartman (1987), analisando a textura de sedimentos coletados em áreas úmidas cercadas por cultivos agrícolas, em comparação com sedimentos de áreas cercadas por pastagens nativas, observaram porcentagens de argila significativamente maiores e, ao mesmo tempo, menores teores de silte e areia nos sedimentos das áreas agrícolas, nas quais as taxas de deposição de argila foram mais elevadas do que nos locais com entorno coberto por pastagens nativas. No presente estudo os solos de vereda adjacentes à área agrícola (lavoura), apresentaram, de modo geral, maior quantidade relativa de silte do que as veredas com entorno conservado ou utilizado como pastagem (Figura 1).

Nas áreas cujo entorno estava submetido às atividades agropecuárias (lavouras e pastagens), pode-se observar,

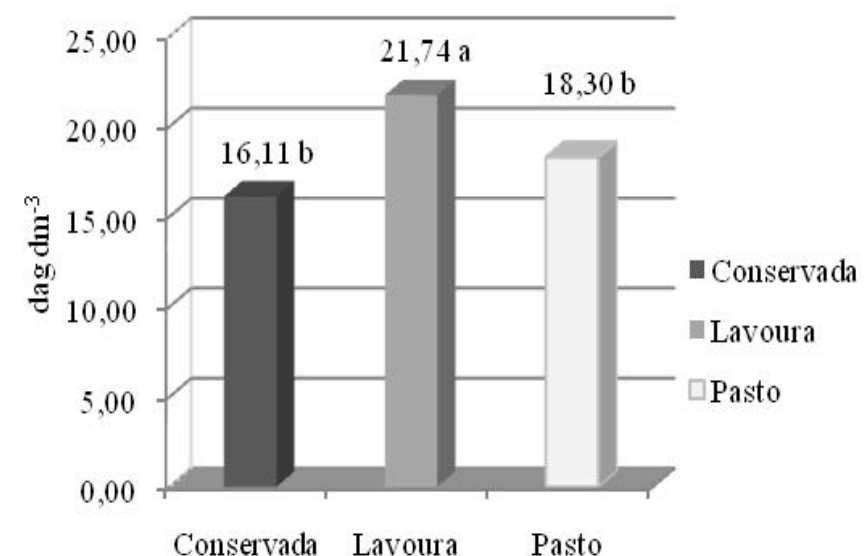

Obs.: Médias seguidas da mesma letra não diferem estatisticamente pelo teste de Tukey a $5 \%$ de probabilidade. Médias das diferentes camadas e posições nas vertentes

Figura 1. Teores médios de silte nas diferentes condições de uso do entorno das veredas tomando-se por referência a vereda com entorno conservado, um aumento significativo do teor de argila na porção mais baixa do relevo (terço inferior) além de uma diminuição relativa desta mesma fração granulométrica no terço superior, principalmente nos locais adjacentes às pastagens. Verificou-se, deste modo e de forma equivalente, um teor maior de areia nas bordas da vereda (terço superior), na área com o entorno utilizado como pastagem cultivada (Tabela 5). Assim, as diferenças texturais observadas neste estudo indicam a ocorrência de processos relacionados à movimentação e deposição diferenciada de sedimentos nas veredas, sendo que esses processos podem ser influenciados pelas atividades agropecuárias realizadas nas áreas circunvizinhas.

\section{CONCLusõEs}

1. Os teores de matéria orgânica do solo (MOS) tendem, naturalmente, a serem maiores no terço inferior das vertentes das veredas estudadas.

2. Nos terços médio e superior das vertentes ocorre maior concentração de MOS na camada superficial do solo $(0-10 \mathrm{~cm})$.

3. No terço inferior das vertentes das veredas, os teores de MOS são mais elevados na vereda preservada e menores nas veredas adjacentes a pastagens e áreas agrícolas.

4. A textura do solo apresenta diferenças dentro das veredas e entre elas, variando com a posição na vertente, a profundidade e o ambiente de ocorrência.

5. Nas veredas estudadas na região inferior das vertentes os teores de argila são maiores em ambientes antropizados.

6. Os teores de silte são, de modo geral, maiores na vereda adjacente à área agrícola.

7. O teor de matéria orgânica e a textura do solo, especialmente na região de fundo (terço inferior da vertente), podem ser bons indicadores das modificações ambientais ocorridas no ambiente da vereda em decorrência do uso da terra nos arredores desses ecossistemas.

\section{Agradecimentos}

Ao Conselho Nacional de Desenvolvimento Científico e Tecnológico (CNPq), à Fundação de Apoio à Pesquisa (FUNAPE), ao Laboratório de Análises de Solos e Foliar da Escola de Agronomia e Engenharia de Alimentos da Universidade Federal de Goiás (LASF/EA/UFG) e à Fundação de Amparo à Pesquisa do Estado de Goiás (FAPEG), pelo suporte financeiro, material ou humano.

\section{LiTERATURA CITADA}

Araújo, G. M.; Barbosa, A. A. A.; Arantes, A. A.; Amaral, A. F. Composição florística de veredas no Município de Uberlândia, MG. Revista Brasileira de Botânica, v.25, p.475493, 2002. 
Araújo, R.; Goedert, W. J.; Lacerda, M. P. C. Qualidade de um solo sob diferentes usos e sob Cerrado nativo. Revista Brasileira de Ciência do Solo, v.31, p.1099-1108, 2007.

Baruqui, A. M.; Santana, D. P. Principais solos sob cerrado e sua aptidão agrícola. Informe Agropecuário, v.6, p.38-52, 1980.

Centurion, J. F.; Cardoso, J. P.; Natale, W. Efeito de formas de manejo em algumas propriedades físicas e químicas de um Latossolo Vermelho em diferentes agroecossistemas. Revista Brasileira de Engenharia Agrícola e Ambiental, v.5, p.254-258, 2001.

CONAMA - Conselho Nacional do Meio Ambiente. Resolução n 303, de 20 de março de 2002. Diário Oficial [da República Federativa do Brasil], Brasília, 13 Mai. 2002.

CPRM - Serviço Geológico do Brasil. Baêta Jr., J. D. A. (Org.). Programa Levantamentos Geológicos Básicos do Brasil. Brasília: CPRM, 2001. (Folha SE. 22 Goiânia). ftp:// ftp.cprm.gov.br/pub/pdf/goiania/goiania_introducao.pdf. 9 Fev. 2009.

Delalibera, H. C.; Weirich Neto, P. H.; Lopes, A. R. C.; Rocha, C. H. Alocação de reserva legal em propriedades rurais: Do cartesiano ao holístico. Revista Brasileira de Engenharia Agrícola e Ambiental, v.12, p.286-292, 2008.

Durigan, G.; Siqueira, M. F.; Franco, G. A. D. C. Threats to the Cerrado remnants of the state of São Paulo, Brazil. Scientia Agricola, v.64, p.355-363, 2007.

EMBRAPA - Empresa Brasileira de Pesquisa Agropecuária. Manual de métodos de análise de solo. 2.ed. Rio de Janeiro: Centro Nacional de Pesquisa de Solos, 1997. 212p.

EMBRAPA - Empresa Brasileira de Pesquisa Agropecuária. Centro Nacional de Pesquisa de Solos. Sistema brasileiro de classificação de solos. 2.ed. Rio de Janeiro: Embrapa Solos, 2006. 306p.

Ferreira, M. B. O cerrado em Minas Gerais: Gradações e composição florística. Informe Agropecuário, v.6, p.4-8, 1980.

Giboshi, M. L.; Rodrigues, L. H. A.; Lombardi Neto, F. Sistema de suporte à decisão para recomendação de uso e manejo da terra. Revista Brasileira de Engenharia Agrícola e Ambiental, v.10, p.861-866, 2006.

Guimarães, A. J. M.; Araújo, G. M.; Corrêa, G. F. C. Estrutura fitossosiológica em área natural e antropizada de uma vereda em Uberlândia, MG. Acta Botanica Brasilica, v.16, p.317-329, 2002.

Junk, W. J. Long-term environmental trends and the future of tropical wetlands. Environmental Conservation, v.29, p.414435, 2002.

Keddy, P. A. Wetland ecology: Principles and conservation. Cambridge: Cambridge University Press, 2000. 614p.

Klink, C. A.; Machado, R. B. Conservation of the brazilian cerrado. Conservation Biology, v.19, p.707-713, 2005.

Lima, P. M. P.; Bahia, V. G.; Curi, N.; Silva, M. L. N. Princípios de erodibilidade do solo. InformeAgropecuário, v.16, p.38-43, 1992.

Liu, X.; Herbert, S. J.; Hashemi, A. M.; Zhang, X.; Ding, G. Effects of agricultural management on soil organic matter and carbon transformation. Plant, Soil and Environment, v.52, p.531-543, 2006.
Maltby, E. Wetland management goals: Wise use and conservation. Landscape and Urban Planning, v.20, p.9-18, 1991.

Martin, D. B.; Hartman, W. A. The effect of cultivation on sediment composition and deposition in prairie pothole wetlands. Water, Air, and Soil Pollution, v.34, p.45-53, 1987.

O'Connell, M. J. Detecting, measuring and reversing changes to wetlands. Wetlands Ecology and Management, v.11, p.397-401, 2003.

Oliveira, C. A.; Kliemann, H. J.; Correchel, V.; Santos, F. C. V. Avaliação da retenção de sedimentos pela vegetação ripária pela caracterização morfológica e físico-química do solo. Revista Brasileira de Engenharia Agrícola e Ambiental, v.14, p.1281-1287, 2010.

RADAMBRASIL. Levantamento de recursos naturais. v.29. Rio de Janeiro: Ministério das Minas e Energia, 1982. 660p. (Folha SD. 23 Brasília).

Ramos, M. V. V. Veredas do Triângulo Mineiro: Solos, água e uso. Lavras: UFLA, 2000. 127p. Dissertação Mestrado

Ramos, M. V. V.; Curi, N.; Motta, P. E. F.; Vitorino, A. C. T.; Ferreira, M. M.; Silva, M. L. N. Veredas do Triângulo Mineiro: Solos, água e uso. Ciência e Agrotecnologia, v.30, p.283-293, 2006.

Ratter, J. A.; Ribeiro, J. F.; Bridgewater, S. The brazilian Cerrado vegetation and threats to its biodiversity. Annals of Botany, v.80, p.223-230, 1997.

Reatto, A.; Correia, J. R.; Spera, S. T. Solos do bioma Cerrado: Aspectos pedológicos. In: Sano, S. M.; Almeida, S. P. (ed.). Cerrado: Ambiente e flora. Planaltina: EMBRAPA-CPAC, 1998. cap.II, p.47-86.

Ribeiro, J. F.; Walter, B. M. T. Fitofisionomias do bioma Cerrado. In: Sano, S. M.; Almeida, S. P. (ed.). Cerrado: Ambiente e flora. Planaltina: Embrapa-CPAC, 1998. cap.III, p.89-166.

SAS Institute Inc. SAS User's Guide: Statistics. Version 9.1. Cary: SAS, 2003. 176p.

Sigua, G. C.; Kang, W. J.; Coleman, S. W. Soil profile distribution of phosphorus and other nutrients following wetland conversion to beef cattle pasture. Journal of Environmental Quality, v.35, p.2374-2382, 2006.

Silva, L. L. O papel do estado no processo de ocupação das áreas de cerrado entre as décadas de 60 e 80 . Caminhos de Geografia, v.1, p.24-36, 2000.

Thomaz, E. L. Dinâmica do uso da terra e degradação do solo na bacia do Rio Guabiroba - Guarapuava/PR. Revista Ra'e Ga, v.13, p.109-128, 2007.

Tiner, R. W. The concept of a hydrophyte for wetland identification. Bioscience, v.41, p.236-247, 1991.

Turner, K. Economics and wetland management. Ambio (Environmental Economics), v.20, p.59-63, 1991.

Walters, D. J. J.; Kotze, D. C.; O'Connor, T. G. Impact of land use on vegetation composition, diversity, and selected soil properties of wetlands in the southern Drakensberg mountains, South Africa. Wetlands Ecology and Management, v.14, p.329-348, 2006. 